\title{
The Application of Well-log Data in Mirco Fault Identification
}

\author{
Jiayi Wu \\ Geoearth Institute, \\ Northeast Petroleum University, \\ Daqing, Heilongjiang 163318, China
}

\author{
Yi Bao \\ Well Logging Company, \\ Daqing Exploratory Drilling Corporation, \\ Daqing Heilongjiang, 163412, China
}

\begin{abstract}
Mirco fault has strong concealment in seismic data interpretation, the fault which is not easy to identify tend to complicate the oil-water relationship in oil-bearing blocks. Combined with the feature of seismic profile reflection to determine the relative change trend of reservoir top interface depth by using logging data, the identification of mirco fault can be achieved effectively. It has a great help for interpretation the oil-water relationship reasonably, looking for advantageous location by using this method to identify mirco fault in W21 block in X oilfield.
\end{abstract}

Keywords-mirco fault; well-log data; seismic profile; oil-water relationship.

\section{INTRODUCTION}

In seismic data interpretation, well-log data is often used to make synthetic seismogram and horizon calibration tracking work, but it has little application in fault interpretation. It's hard to identify mirco faults with strong concealment by using conventional geophysical methods. Various fine seismic description technology has been used to identify the mirco faults, such as ant tracking technology, seismic coherence techniques ${ }^{[1]}$ and seismic attribute analysis ${ }^{[2]}$. But it still demands large amount of seismic data ${ }^{[3]}$.

The $\mathrm{X}$ oilfield is located in the transitional slope belt from Daqing Placanticline to Sanzhao Depression in the North of Songliao Basin, the developed objective layer is Putaohua oil layer in segment 1 of the lower Cretaceous Yaojia member. With no large anticline structure, the block only formed some faulted-block traps under the fault action, which has low structure amplitude. The distributary channel sand body is the main reserving space of $\mathrm{X}$ oilfield, the sand connecting of which is weak on the landscape. Due to the primary time of hydrocarbon expulsion of the source rocks in Qing1 member is earlier than the deposit of Sifangtai formation, $\mathrm{X}$ oilfield is the favorable directional zone of hydrocarbon migration, which has the paleotectonic framework of West high East low. Since exploited in 1999, the main way to increase reserves of $\mathrm{X}$ oilfield is to seek small partial micro-structure which is favorable of hydrocarbon accumulation. The quality of seismic data is hard to fulfill the demand of the high- precision micro fault identification for the lack of 3D seismic data.

The current well spacing density in W21 block has been reached to $0.25 \times 0.25 \mathrm{~km}$, which provided favorable conditions to analyze the structure depth change. On the basis of well logging information in the same well array, this paper analyzes the tectonic location tendency of top Putaohua reservoir with depth. Combined with the features of seismic profile reflection, this paper identifies micro faults of $\mathrm{X}$ oilfield, which has important significance in oil-water relationship interpretation.

\section{FAULT IDENTIFICATION IN THE SEISMIC SECtion}

Usually, the large-scale fault is identified by observing the change of the seismic event on the seismic sections. We can make sure there is a fault when one or two of the following characteristics exist in a very significant status. (1) Seismic event interrupted.(2) Seismic event wrapped.(3)The number of seismic event changed, increase or decrease.(4) The width of seismic event changed.(5) Strong-phase and weak-phase interchanged.(6) Seismic event forked or merged. The following figure set an example of the main characterization of conventional fault in Putaohua reservoir in X oilfield.

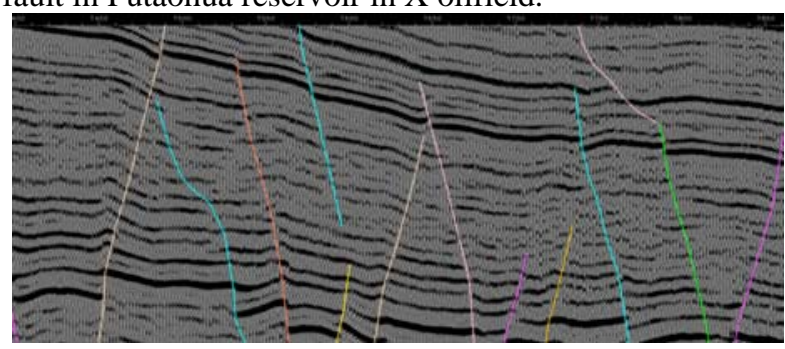

Fig.1. The characterization of conventional fault on a seismic profile.

\section{The ApPLICATION OF WELL-LOG DATA IN FAUlt IDENTIFICATION}

During the period of the lower Cretaceous Yaojia member, Putaohua reservoir deposited through the slow lacustrine ${ }^{[4]}$ regression of Qing2-3 sedimentary period, the large lake shrinkage of early Yao1 sedimentary period and the large lake transgression of late Yao1 sedimentary period. The large areas of river-delta reservoirs in LST in Yao1 member are closely adjacent to the overlying ash black-black mudstones with semi-deep and deep lacustrine facies ${ }^{[5]}$ in Yao2-3 member. The location of top Putaohua reservoir is easy to recognize in logging curves, showing as a V-shaped lowest point in resistivity logging curve, a rising trend of gamma ray logging curve and a descending trend of acoustic logging curve.

W21 block in X oilfield is a typical single E-W monocline. Seeing from 3 wells or more in a well line from east to west, this paper make the interwell attachment of top Putaohua member from high point of 
the structure to low point of the structure. If fault exists between two wells, there will be an obvious sharp slope of the interwell segment in comparison of the line segment slope between other two wells in the same line (Figure 2(case2), Figure 2(case3)), otherwise, the sharp slope does not exist (Figure 2(case1)).

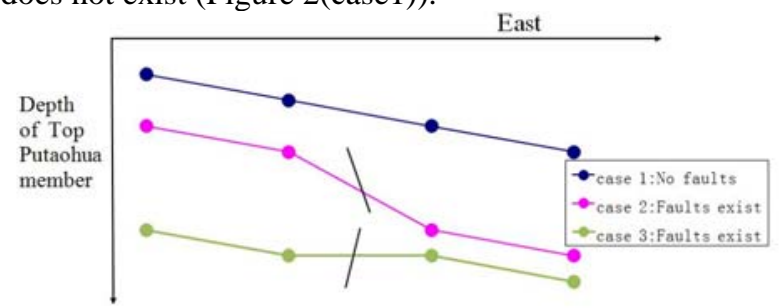

Fig.2. The relation between faults exist and depth change

In the actual well-line investigation, the slope of line segment could be calculated in the formula below,

$$
k=\frac{D 2-D 1}{X 2-X 1}
$$

in which, $\mathrm{k}$ - slope of line segment, D1 -top Putaohua member depth in well1, D2 - top Putaohua member depth in well2, X1 - horizontal position of well1, X2 horizontal position of well2.

By calculating, the method shown in Figure 2 is effective in recognizing fault position.

\section{A. Example 1}

There are 6 wells in $\mathrm{W}^{*} 6$ well line (Figure 3 ), making the top Putaohua member line between neighboring wells and calculating relative slope of line segments. In calculation, the slope of line $\mathrm{AB}, \mathrm{BC}, \mathrm{CD}$ and $\mathrm{DE}$ is $0.03591,0.08856,-0.02626$ and 0.02642 relatively. The slope of line CD is obviously different from that of other 3 lines. In correspond with relative seismic section, the fault position between $\mathrm{W} 1-*_{-} 3$ and $\mathrm{W} 1-*_{-} 4$ can be distinguished definitely. Putting the recognized fault into the interwell profile of $\mathrm{W}^{*} 6$ well line, it can be find that there is a fault in the theoretical position, which has an important influence on the oil-water relationship. The existence of fault solves the oil-water inversion problem and makes oil-water relationship more exact and reasonable (Figure 4).

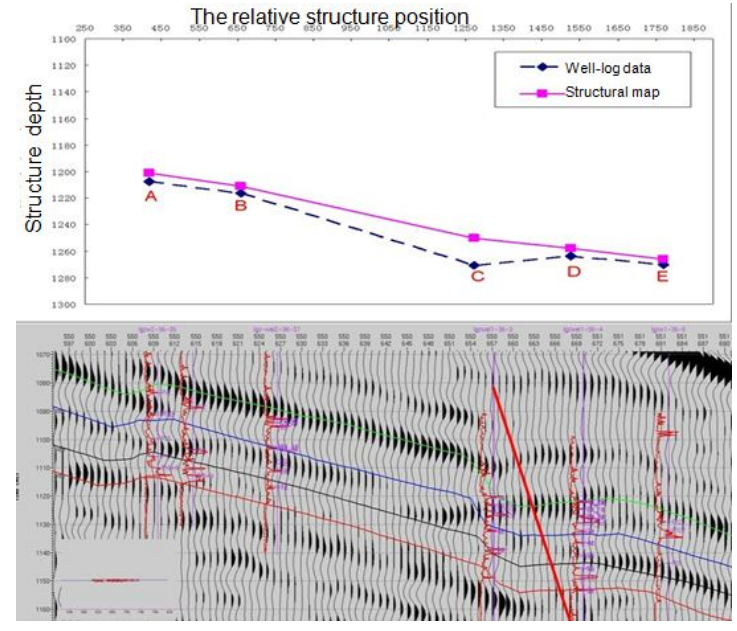

Fig.3. The relative structure position in $\mathrm{W}^{*} 6$ well line and seismic profile

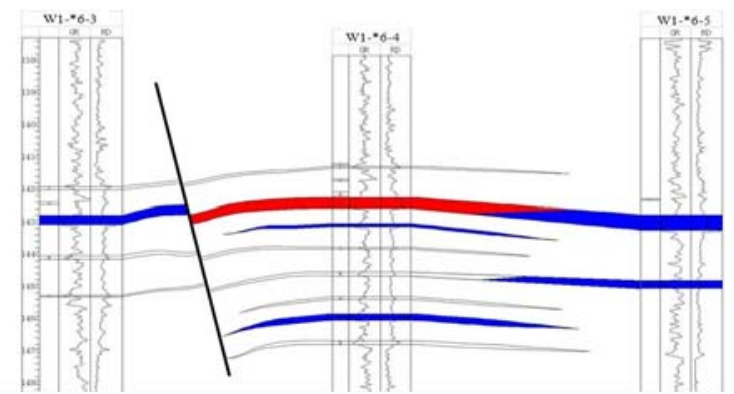

Fig.4. The influence of fault on oil-water relationship in $\mathrm{W}^{*} 6$ well line

\section{B. Example 2}

There are 7 wells in the well line that micro fault may exist. By making the top Putaohua member line between neighboring wells and calculating relative slope of line segments, the slope of line $\mathrm{AB}, \mathrm{BC}, \mathrm{CD}, \mathrm{DE}, \mathrm{EF}$ and FG is $0.0448,0.1111,0.0119,0.0126,0.0542$ and 0.0415 relatively (Figure 5). By analyzing those data, line BC, $\mathrm{CE}$ and EG are similar with the condition shown in Figure 2(case3). In correspond with relative seismic section, it indicate that a micro fault exists on the left of point $\mathrm{E}$, which is in the west part of W1-*-4. 


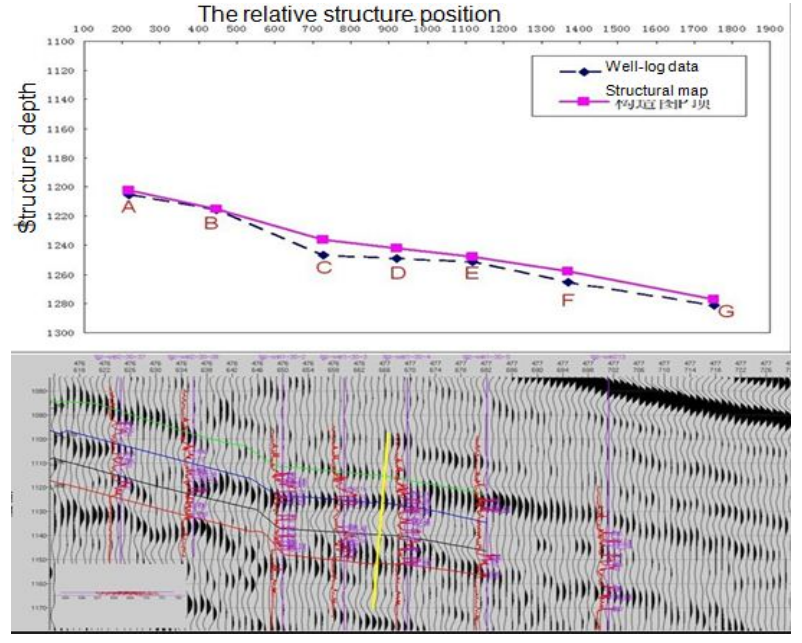

Fig.5. The relative structure position in $\mathrm{W}^{*} 0$ well line and through-well seismic profile

The method to identify faults by using the interwell depth drop characteristic of top Putaohua member plays an important role in seeking micro faults in the study zone. Figure 6 is an instance of identifying micro fault in W21 block. The appearance of fault help to explain the phenomenon of oil-water inversion.

\section{PRACTICAL ApPlication EVALUATION}

According to the following steps to complete the mirco fault identification:

(1) Read the structure depth of the top Putaohua member according to curve signal feature among the different wells in the same line.

(2) Making cross-plot between relative structure location and relative structure depth, calculate the slope of deep attachment between wells.

(3) Determine whether there is a line slope of the slope is very different from other segments, if large decline or lifting up happens, follow next step, if not, there is no mirco falut between wells.

(4) If the first case in step 3 exists, looking for specific location in the seismic section, determine whether there is a mirco fault further combined with seismic section for detail analysis.

(5) Carry out actual deployment and perforation according to the recognition result combined with fluid property judged from well-log data.

Auxiliarying to identify fault according to gap characteristics of top Putaohua member, that played an important role in looking for mirco fault in survey region. The following figure provided an example to us that identified the mirco fault using the provided method. The phenomenon in the process of oilfield exploitation injection-production effect is prominent and oil-water relationship inversion can interpreted reasonably since the recognition result of mirco fault.
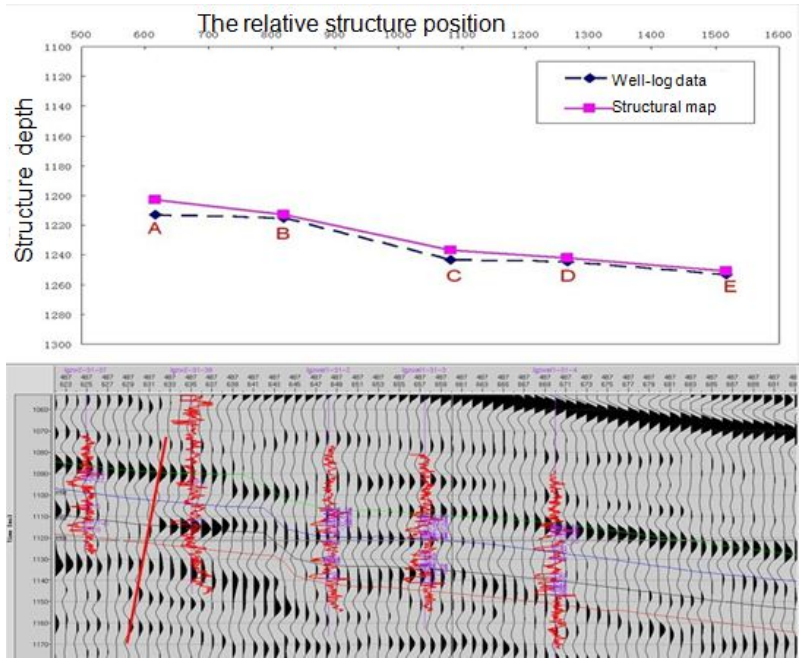

Fig.7. The relative structure position in $\mathrm{W}^{*} 1$ well line and through-well seismic profile

The wells on the left and right side of micro fault are Wei2-*-37 and Wei2-*-38. In the process of oilfield injection-production, Wei2-*-37 is a water- injection well and Wei2-*-38 is a pumping well, the connected sand bodies of two wells are perforated to exploitate. But the actual exploitation data indicates that the water injection rate of Wei2-*-37 doubled but the production of Wei2-*-38 reduced to 2t/d after 6 months, which shows that the water flooding development effect is not noticeable. This illustrates that micro faults play a blockage role in the circulation of injected water.

\section{SUMMARY}

The method that identifying possible micro faults in single anticline block by using well information to find tectonic position change proves to be realistic and effective. Not only decreases multiple solutions of seismic recognition, but also is this method easy to operate. Though the study zone in this paper is a single anticline block, it is also an effective way to find micro fault in complex structures by dividing the complex structure into unitary structural blocks on the basis of seismic recognition of the tectonic setting in complex region, which is helpful to choose the favorable position in the developed blocks.

\section{REFERENCES}

[1] Tie-jun Qu, Ruinian Jiang, Dai Wang, et al. Response of Underground Pipelines Subjected to Partially Coherent Seismic Excitation. Journal of Pipeline Systems Engineering and Practice Vol.4, No.4 (2013).

[2] Lialekol P.E., Oskouei M., Keshavarz N., et al. Seismic Attributes Integration by GIS for Fracture Detection. Energy Sources Part A: Recovery, Utilization, and Environmental Effects. Vol.36, No.9 (2014), p. 974-981.

[3] H. Almalki, K. Munir. Efficiency of seismic attributes in detecting near-surface cavities. Arabian Journal of Geosciences. Vol.6, No.8 (2013), p. 3119 - 3126. 
[4] Adedosu T.A., Sonibare O. O., Tuo J., et al.The Occurrence of Lacustrine Depositional Setting in the Mamu Formation, Anambra Basin, Nigeria. Energy Sources, Part A: Recovery, Utilization, and Environmental Effects. Vol.36, No.4 (2014) , p. 374-382.
[5] Caineng Zou, Lan Wang, Ying Li, et al. Deep-lacustrine transformation of sandy debrites into turbidites, Upper Triassic, Central China. Sedimentary Geology.Vol.265-266(2012), p. 143-155.

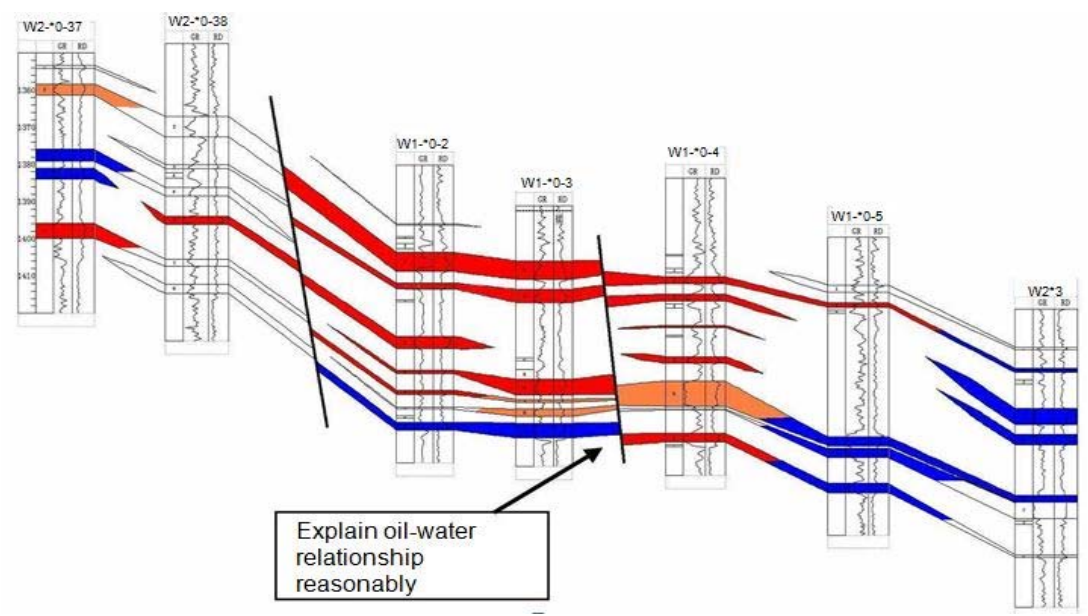

Fig.6. Reservoir profile map across $\mathrm{W}^{*} 0$ well line 